\title{
Trends in the rational use of municipal solid waste
}

\author{
Sergey Tyaglov, Natalia Rodionova, and Susanna Bugayan* \\ Russian State University of Economics Москва, Russia
}

\begin{abstract}
Is not yet possible to create a full-fledged municipal solid waste management industry in Russia, as private investors currently do not consider this area promising for investment, even if there is a positive domestic experience. Since the механизмыfree market mechanisms in this industry have not worked, it is the state that has the main task of forming all the infrastructure necessary for MSW management, so the purpose of this article is to consider the main directions of MSW use in accordance with global trends and the possibility of using the experience of other countries that have achieved high results in this area. Today, Russia generates about 70 million tons of municipal solid waste (MSW) per year. According to the figures laid down in the national project "Ecology", by 2024, 60\% of garbage should be processed, that is, sorted, and then sent for recycling, $36 \%$ of the total volume of waste should be recycled. To do this, it is necessary to additionally build capacities capable of sorting 37.1 million tons of MSW. At the same time, enterprises operating in this segment, have a shortage of financial resources - half of the approximately two hundred operators in the country have cash gaps, accounts payable and receivables are growing, and operations are becoming unprofitable. In these circumstances, it is very important to consider the mechanisms that can increase the attractiveness of the industry for business and ensure its profitability.
\end{abstract}

\section{Introduction}

The priority goal of the national project "Ecology" is to create a comfortable and safe environment, which implies achieving the following tasks by 2030 :

- creation of a full cycle of municipal solid waste management system;

- 100\% toilet recycling of waste and halving the amount of garbage that is buried in landfills;

- 2-fold reduction in emissions of hazardous pollutants;

\footnotetext{
* Corresponding author: kisusanna@yandex.ru
} 
- complete elimination of the most dangerous objects of accumulated environmental damage and ensuring the ecological improvement of water bodies, including the Volga River, Lake Baikal and Lake Teletskoye [1].

According to Article 1 of Federal Law No. 89, municipal solid waste consists of three categories of garbage -waste generated during individual consumption by individuals (household garbage), similar garbage generated during the activities of legal entities, as well as items and things that are no longer suitable for use. Since 2019, the processes of solid municipal waste management and disposal are managed by regional operators and represent an independent public service.

The basic idea of reforms implemented since 2019, is the introduction of separate collection of municipal solid wastes in major cities of the Russian Federation on two fronts the "dry" waste that is recyclable (glass, metal, plastic, paper, etc.) and "mixed" or "wet" garbage, which includes mostly food waste. According to studies and the experience of other countries, about half of the waste can be recycled, which significantly reduces the load on landfills and provides less recycling, which has a positive impact on the environment [2]. Regional ministries of housing and utilities and operators involved in garbage collection develop special instructions for residents explaining how to sort and dispose of garbage (Figure 1), but not all cities in the country have implemented the possibility of such separate collection, due to the elementary lack of tanks for two waste sorting options.
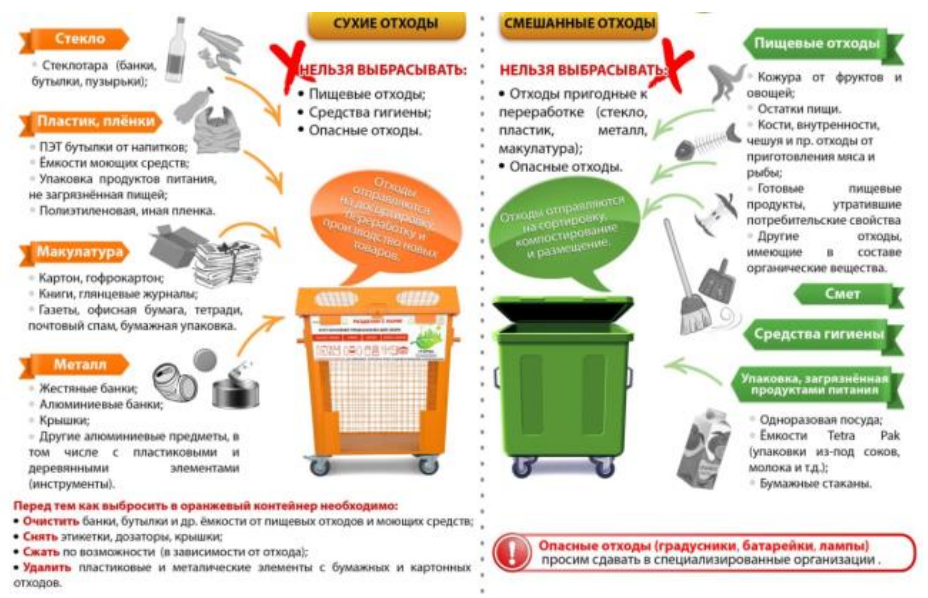

Fig.1. Two-container waste management system (memo for the public) [3]

However, the results of the garbage reform is not yet comforting, as in as in other countries, build factories, where the trash is scheduled to hydrogen - eco-friendly energy source, environmentally friendly, used for filling, e.g. electric vehicle, powered by a hydrogen fuel cell, Russia has still not solved the problem of the vast number of unauthorized landfills, not to mention other aspects of waste management. The low level of waste treatment is a consequence of the lack of the necessary high-tech infrastructure for waste treatment and disposal, the creation of which is provided for by the federal project "Integrated system for solid municipal waste management".

\section{Research methodology}

The main global trends in the use of municipal solid waste include the following:

- Transition to a closed-loop economy based on the use of secondary raw materials (Figure2). 

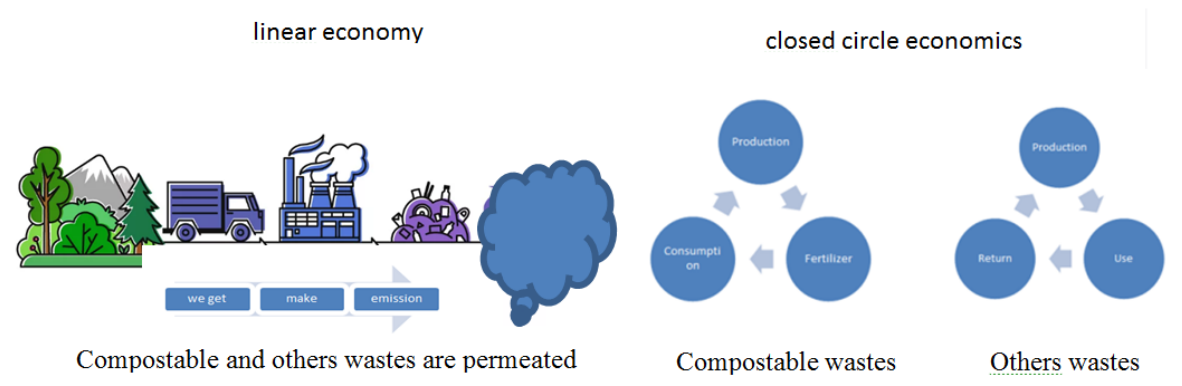

Fig. 2. Scheme of MSW use in two types of economies [4]

- Reduce waste transportation costs through the use of innovative technologies and adaptive management of waste collection and recycling processes.

- Increasing the proportion of MSW usedй for processing or incineration, reducing the proportion of MSW used for landfill disposal

- The growing popularity of such a waste management method as composting, which involves the possibility of eco-friendly disposal of food and plant waste, due to which compost is formed, which acts as a soil for a garden or vegetable garden and serves as an excellent alternative to chemical fertilizers.

- Increasing the popularity of the use of recyclable materials for the production of various personal items, including the popularization of this direction by well - known brandsmanufacturers of clothing and footwear.

\section{Research results}

A lot depends on the mentality of the population, its intentions and ability to sort garbage and properly dispose of it. For example, in some municipalities in Japan, residents sort garbage into almost 30 different fractions, in most regions-into 11-15 types. In our country, however, it is not yet possible to master the division into two types. In this context, Japan's protected areas are very interesting to study - the small territory of the country does not allow for the creation of new large landfills, and the national program of widespread modernization does not involve non-ecological disposal by incineration.

Currently, developed countries such as Japan and Switzerland are actively developing new technologies for MSW management - composting and biogasification. The method of packaging food waste in a bioplastics bag with its subsequent composting is becoming quite common, and the resulting biomass is used to generateelectricity. Producers also take responsibility for sharing the financial burden with consumers of goods and maximize the recycling of secondary raw materials.

If you study the specific experience of sorting garbage by Japanese residents, then on the first floors of houses there is a platform for separate garbage collection. Very often, MSW collection is organized on the basis of a voluntary collective collection - that is, when any group of people, for example, neighbors in a city block, registers with the municipality and collects various fractions of recyclable materials. There is a similar experience in Rostov-onDon, but without official registration. But at the same time, if in our country, this is done on a completely voluntary basis, without a specific system and residents each time we agree with the district administration on the garbage disposal, then in Japan, a municipality contracts with companies on a regular basis, take out and recycle the recyclables, as well as pay citizens participating in the process of separate collection (Fig.3). The most interesting thing is that Japanese experts claim that this system was imported from the Soviet Union, when, for example, schoolchildren bypassed their neighbors and collected waste paper. 


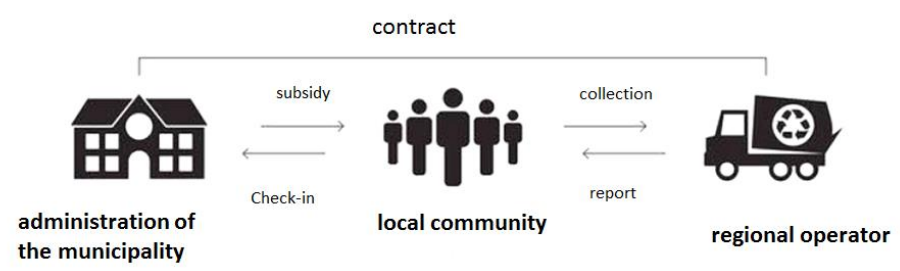

Fig. 3.Waste management algorithm for collective MSW collection in Japan [5]

Let's look at a local example of how such groups of volunteers work on the example of the «Forest SKA Initiative Group", as the group calls itself in social networks. Thus, in less than a month from 21.03.21 to 17.04.21, the group collected $820 \mathrm{~kg}$ of glass (for the entire period of the group's work- $6810 \mathrm{~kg}$ ), $308 \mathrm{~kg}$ of waste paper (for the entire period of the group's work-1072 kg), $14 \mathrm{~kg}$ of metal (for the entire period of the group's work - $59 \mathrm{~kg}$ ) in the green zones of Pervomaisky district, as well During the specified period, only $1,142 \mathrm{~kg}$ $550 \mathrm{~g}$ of recyclable materials were collected, and for the entire period of the group's work, $7951 \mathrm{~kg} 150 \mathrm{~g}$ less waste was sent to the landfill, that is, this amount of recycled materials received a second life. This is the result of the work of only 10-15 people, so we can confidently say what a large-scale effect will be with the proper operation of the collective collection mechanism in our country. It is also noteworthy that the work of such groups solves two problems at once - not only the correct disposal of income, but also the cleaning of territories from garbage, including unauthorized landfills [6].

The Japanese MSW management system is aimed at increasing the motivation of the population to separate collection - payment for garbage is made based on its volume, and if there are no incentives for responsible waste management, then the results of the garbage reform are unimpressive and even more so, allow experts to talk about the failure of the "garbage" reform.

\section{Discussion of the results}

In Russia, almost $90 \%$ of garbage is sent to landfills, while recycling is much more efficient (7\%) and burning is applied very little. The experience of developed countries proves, that even incineration of garbage can be completely eco-friendly, if it uses technologicallye инновации advanced innovations and improves the quality of equipment operation.

The most serious problem is that the infrastructure for sorting and recycling garbage is insufficient, the introduction of new capacities is lagging behind the plan, while the formation of active population groups ready to sort garbage is becoming more intense. That is why, at the regional level of MSW management, it is very important to ensure both an optimal balance of landfill, incineration and recycling and waste, and to create a common strategy and scheme for MSW management aimed at achieving this balance. An example of this should be the experience of other countries, such as Italy, Switzerland, Denmark, and Finland, where $40-50 \%$ of all MSW is sent for processing (Figure 4). 


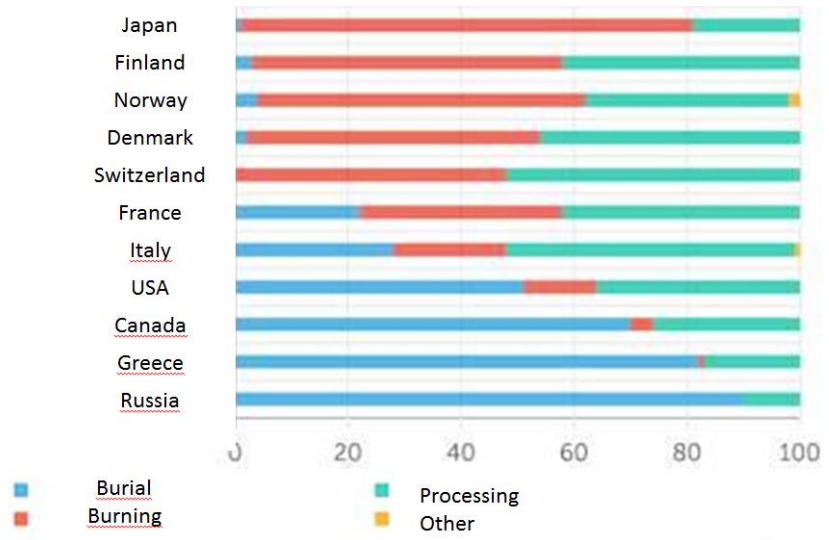

Fig.4. MSW utilization methods in Russia and foreign countries, \% [5]

From all of the above, it follows that it is the provision of the necessary infrastructure that underlies the successful implementation of MSW management measures [7]. In this regard, let's look at the example of the Rostov region, how the infrastructure is being prepared to improve the processes of garbage collection, processing and disposal.

Chisty Gorod Group of Companies invested more than 1.7 billion rubles in the construction and reconstruction of solid municipal waste management facilities in the Rostov Region.:

- modernization of the waste sorting complex in the Leventsovsky microdistrict of Rostovon-Don in the amount of 250 million rubles;

- construction ofого the inter-municipal ecologicaloго waste processingего complex A (hereinafter referred to as the IECC) in Volgodonsk in the amount of 1 billion rubles; - completion of the first stage Myasnikovsky MEOK in the amount of 500 million rublesй.

The construction of MEOCS is part of the largest investment program implemented by Chisty Gorod in the Don region . By 2023, 8 complexes will be built on the territory of the region, with investment investments amounting to 5.3 billion rubles. Chisty Gorod is not only the largest private investor in the waste management system infrastructure being created in the Rostov Region, but also the first to build and launch a new powerful waste processing complex here.

Ecotrans LLC, which built the first stage of the Neklinovsky MEOK for MSW collection from the municipal waste management system, also takes part in creating the infrastructure for MSW management Taganrog, Neklinovsky, Matveevo-Kurgan, and Kuibyshev city districts. Incoming MSW will be automatically sorted into fractions, briquetted and sent for processing. The non-mobile part of the waste will be placed on the landfill map, at the base of which a geomembrane will be laid, which protects the soil and groundwater from contamination. It is assumed that following the first five years of operation of the new MSW infrastructure created for processing in the Rostov region, the share of recycled waste will increase sevenfold: from 5\% in 2018 to $35 \%$ in 2024 [8].

Optimization of integrated MSW management also involves the use of modern digital technologies. The digital platform developed by MTS for managing the removal of municipal solid waste provides monitoring and control of MSW accumulation, their transportation to waste transfer and sorting stations, waste processing plants and landfills in accordance with the regional waste management scheme. As part of the solution, garbage containers are equipped with filling monitoring sensors, garbage trucks with navigation equipment and video recorders, stations and landfills with weight control systems, or integration with existing systems and equipment is provided. 
MSW removal management allows you to track the history of events along the route (organization of geofences of places where garbage containers and landfills are installed, control of container transportation and time spent in installed geofences). Transport management provides automatic planning of optimal MSW export routes depending on the fullness of containers, recording of departures from the route, prompt notification of the dispatcher/logistician, etc. (Fig.5).

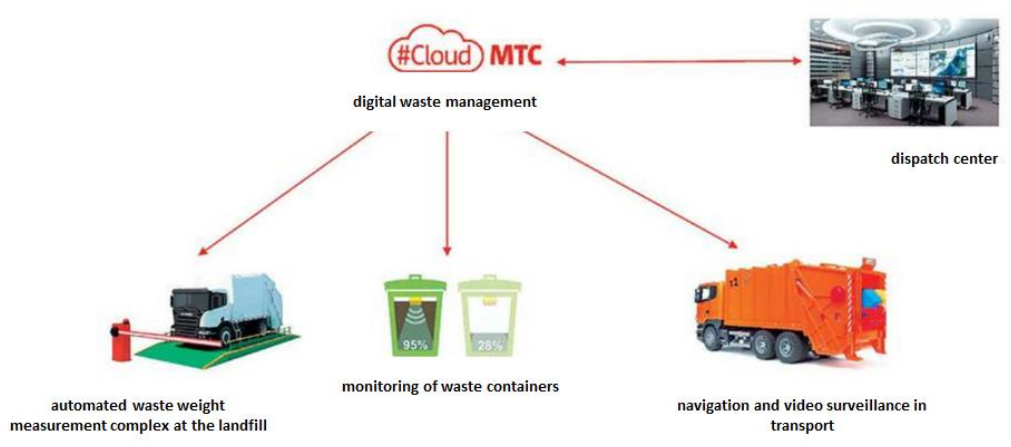

Fig. 5. Structure of the organization of digital MSW export management [9]

The use of the digital platform provides authorities and regional operators with realtime complete, objective and reliable data on the filling capacity of garbage containers, completeness and timeliness of MSW removal, compliance by operators of the regional waste management scheme with the terms of contracts, as a result, timeliness and completeness of MSW removal, and prevention of waste removal to unauthorized places. By optimizing the routes of garbage trucks (based on operational and objective data on MSW accumulation, road conditions, and the lack of fuel theft), waste collection and transportation costs are reduced by up to $15 \%$. Currently, the solution is being implemented in the Samara, Moscow, Sakhalin, Nizhny Novgorod, and Smolensk regions and, according to regional operators, reduces the cost of fuel and lubricants and vehicle maintenance by at least $10 \%$.

Now, in principle, a lot of innovative projects related to optimizing the MSW management process are supported, since these projects not only improve the MSW collection algorithm itself, but also significantly reduce operator costs [10]. For example, manufacturers and sensors for monitoring the filling of Wasteout bins Wasteout provide the following data: the largest component in the tariff for garbage collection is directly the transportation of garbage, amounting to $60-70 \%$. It can be reduced by reducing unnecessary car trips to half-empty tanks. Operators who already use such a service estimate savingsю in operating costs (fuel and motor resources) from $20 \%$ to $50 \%$, annual savingsapproximately $10 \%$ of the company's income, with a very fast payback of the device - from 7 to 9 months [4].

\section{Conclusions}

In this regard, to solve the problems of waste management in Russia, it is necessary to take into account a number of important principles:

- a clear understanding of who is responsible for the disposal, collection, sorting and disposal of garbage;

- commitment of the population to cooperate with municipalities in the implementation of measures to address the problems of MSW management; 
- continuous education of the general public, including children and young people, on waste reduction and compliance with the rules of separate collection. This point is implemented quite simply, and in our region, in particular, there are examples of environmental education and education of children, including in practice-the task is to make sure that this experience is not isolated;

- the task of municipalities is to ensure the financial viability and stability of MSW management schemes. Private operators should be provided with a business environment that allows them to operate profitably;

- clear binding of payment for garbage collection to its volume, as well as the existence of a system of penalties for violating the rules for separate garbage collection or its disposal in the wrong place. Now there is a very strange situation on this issue - the amount of payments from the population has increased several times, and in some regions even tenfold with a huge regional differentiation-from 244 to 1411 rubles per cubic meter, but there are no tangible, qualitative changes in MSW management.;

- creating opportunities for separate collection of garbage "on the ground" - this means providing the necessary volume of all cities and rural settlements with containers for separate garbage collection. The situation when a person needs to go to Mega for proper disposal of batteries, and to hand over glass jars from under baby food-to Zapadny (if we consider the city of Rostov-on-Don) is not normal, and such a garbage collection system only creates the appearance of sorting it, and does not solve the real problem.

If we talk about the management of MSW at the Federal or regional level, it should be noted that recycling is a very profitable business, so management strategy TCR must include measures to support business related to processing and recycling, as by providing different incentives (tax, subsidy interest rate on the loan, direct subsidies), and by the development of investment projects under the scheme of public-private partnerships. The experience of Switzerland, which has made very significant progress in MSW management, shows that this industry has a huge potential both from an economic and environmental point of view - more than 90 percent of used glass containers end up in processing plants, and almost a third of printed products are also returned to recycling points. Existing recycling technologies allow us to return up to 70 percent of the waste to circulation.

If we consider the domestic practice of MSW management, then the experience of Krasnoyarsk is interesting to study, where paving stones and road bumpers are made from crushed old car tires, and the technology of adding crushed rubber to asphalt is being worked out (which makes it possible to increase the wear resistance of the road surface several times). The economic benefits here are quite obvious - more than 400 thousand cars are registered in the regional capital, and each of them on average "wearsout" two sets of rubber in two years-this is about three million tires, which actually become free rawm materials for production.

The 2020 pandemic and the associated economic downturn led to a drop in collection of payments toe the MSW e-sector. Investment projects related to sortingoй and processingoй, were frozen at the very start of the investment cycle, which involves the creation of newx productionx areas and the planning of long-term transactions. This situation has developed due to the fact that this process involves funds from large network players who have problems with payments and tariffs. At the same time, most investments in new infrastructurey are made by regional operators who are looking for partners in the form of construction organizations and third-party investors. Also, the increase in the exchange rate adversely affected the planы of purchasing foreign equipment and components. It is also necessary to take into account the general economic situation : in times of instability, investors are very cautious about new investment directions, do not rush to invest in innovative projects, and sometimes even resort to disinfection. 
Given the current situation, not only individual regions, but also Russia as a whole should more actively and systematically use the experience of countries that have significantly advanced in the issue of effective waste management. For example, by reducing the amount of waste generated, in particular, by introducing restrictions on disposable goods and packaging [11].

Despite the fact that the hugemscale of our country itself suggests the need for a comprehensive system of separate waste collection, the national project "Ecology" sets out rather its individual parts, and a holistic MSW management mechanism has not been proposed. On the other hand, it takes a certain amount of time to create or increase the production capacity necessary for proper disposal, sorting and recycling, since without this, separate collection efforts and local waste disposal projects are useless.

The volume of required investments is 300 billion rubles, but only a third of them are federal budget funds, while the rest is planned to be attracted by private investment [12]. It is quite obvious that the safest option for private businesses is concessions. Measures to support investors in MSW infrastructure facilities are already in place, in particular, project financing is provided in the form of participation in the authorized capital of investors and providing guarantees for loans, loans and other obligations of investors. This is really important support for the industry. However, until there is an effective, transparent and understandable MSW management mechanism for all participants with step-by-step measures supported by organizational and financial support from the state, qualitative changes in the field of MSW processing are not expected.

The article was prepared with the financial support of the RFBR in the framework of the scientific project No. 19-010-00860 "Formation of an organizational and economic mechanism for managing the sustainable development of regional innovation systems based on the best available technologies"

\section{References}

1. S.G. Tyaglov, E.V. Parada, B сборнике: The European Proceedings of Social \& Behavioural Sciences, 211 (2019)

2. S. A.Bugayan, Journal of Economic Regulation (Voprosy regulirovaniya ekonomiki), 11(1), 90 (2019)

3. "Garbage" reform can't move out of the landfill, https://expert.ru/expert/2020/41/musornaya-reforma-ne-mozhet-s_ehat-so-svalki/ Accessed on 21.05.21

4. L. Kolbina, Expert Ural, 5, 14 (2019)

5. N. Ulyanov, Expert, 5, 34(2021)

6. S. G.Tyaglov, E. V. Parada, S. A.Bugayan. Leader (People. Ideas. Progress. Unity. Result). Collection of articles of the First Management Forum of the Khanty-Mansiysk Autonomous Okrug-Ugra, 140, (2019).

7. N.G. Kuznetsov, S.G. Tyaglov, M.A. Ponomareva, N.D. Rodionova, Process Management and Scientific Developments. Materials of the International Conference, 14 (2019)

8. N. Ulyanov, Expert, 46, 39 (2020)

9. Digital transformation. Expert-Ural, 3, 14 (2020)

10. S.G. Tyaglov, S.A. Bugayan, Journal of Economic Regulation, 12(1), 37 (2021).

11. A. Muzhshchinsky, Expert-Sibir, 4, 28 (2017)

12. M. Zamarin, Koronakrizis slows down the garbage reform, https://expert.ru/2020/09/25/koronakrizis-tormozit-musornuyu-reformu/ 